\title{
Impacts of enclosures in rehabilitation of degraded rangelands of Turkana County, Kenya
}

\author{
John N. Kigomo* and Gabriel M. Muturi \\ Kenya Forestry Research Institute, P.O. Box 20412-00200, Nairobi, Kenya.
}

Accepted 31 May, 2013

\begin{abstract}
The role of enclosures in range rehabilitation was investigated through a case study at Kalatum in Turkana County where the use of enclosures and establishment of fodder species were demonstrated to the local communities in late 1980's. However, documented information on the impact of enclosures is scanty. Rehabilitation impact was evaluated through ecological sampling in fenced and unfenced areas and comparison of vegetation variables. The technology adoption was evaluated by Geographical Information System (GIS) techniques to determine the extent of enclosure expansion using social fence by local community. Results showed a higher density of fodder species in the fenced than in the unfenced areas $(p=0.019)$. For example, Acacia tortilis attained a density of 204 trees ha ${ }^{-1}$ in the fenced areas as compared to 74 trees $\mathrm{ha}^{-1}$ in the unfenced area and the average ground cover of Crysopogon plumulosus was $36 \%$ in the fenced as compared to $4 \%$ in the unfenced area. Technology adoption was good, as evidenced from fence expansion from the initial 5-ha established under research trials for 23ha community enclosures. The findings show the importance of involving local communities during the project cycle and recommends up scaling of this technology among pastoral communities in Kenya.
\end{abstract}

Key words: Enclosure, rehabilitation, technology adoption, Geographical Information System (GIS) and Turkana.

\section{INTRODUCTION}

Range degradation has become a common phenomenon in Kenya's drylands, thereby threatening the survival of indigenous communities who have long depended on range land resources. According to the Government of Kenya (2007), drylands support $30 \%$ of human population and $70 \%$ of livestock and the bulk of wildlife that support the tourism sector. In the past, pastoralism thrived under traditional management practices that were characterized by delineation of seasonal grazing areas to support nomadism (Sitters et al., 2009). The practices facilitated range resource resilience through periodic relief of grazing pressure between the foraging intervals. Development interventions have discouraged nomadism in favour of sedentarization for effective provision of social amenities without regard to ecological implications. Consequently, these settlements have become degradation nuclei; with resource degradation intensity increasing towards the settlement centres (Okoti et al., 2004; Kariuki et al., 2007). The main factors associated with this trend include over-exploitation of resources due to localized increase in human and livestock populations, climatic changes due to insufficient and unreliable rainfall and poverty. To arrest this alarming degradation, it is important to design economically feasible, socially acceptable and ecologically viable management and conservation strategies for vegetation resources.

Numerous drought incidences have been reported in Turkana County whose impacts have been devastating 


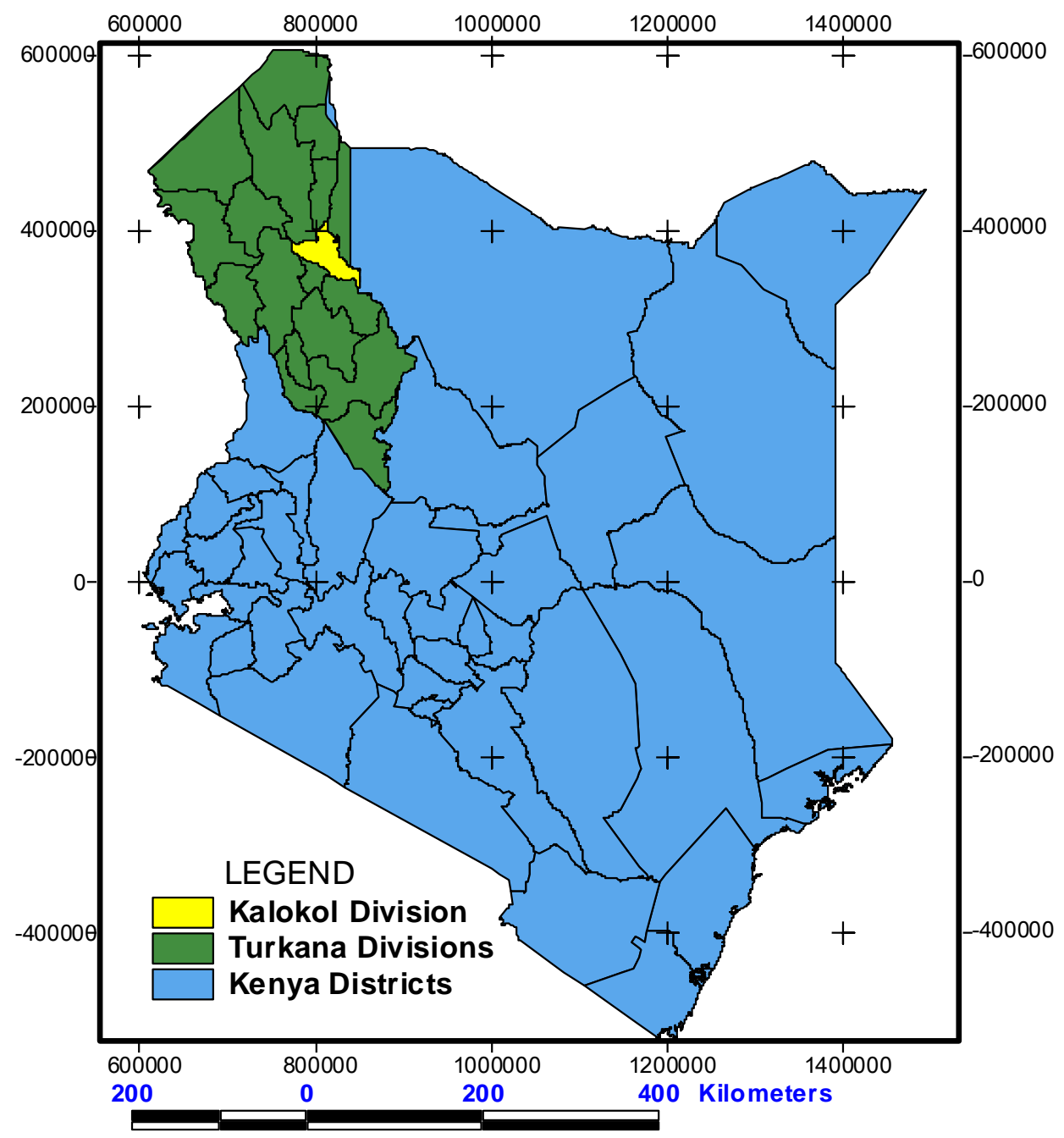

Figure 1. Location of Turkana County in northern Kenya.

(UNEP, 2000). Past reactionary measures included famine relief, sporadic food for work activities and establishment of irrigation schemes. These led to the establishment of settlements resulting into prevalent resource degradation. In the early 1980 s, several programmes were initiated to address the emerging degradation problems. Turkana Rural Development Program (TRDP) was one such program that was funded by the Norwegian Agency for Development Co-operation (NORAD). Kenya Forestry Research Institute (KEFRI), the leading implementing agent for this program and other stakeholders were involved in range rehabilitation by use of enclosures, range re-seeding and planting of fodder trees through water harvesting. This involved demonstration of rehabilitation technologies and sensitising the local communities on the potentials of introduced technologies. Although the enclosures have been one of the range rehabilitation technologies in northern Kenya, scientific studies on their socio-economic and ecological importance are scanty. This paper presents an evaluation of about 25 year old
Kalatum rehabilitation site in Kalokol division where a research and development plot was initially established in 1986. The overall objective was to investigate contribution of enclosures as a tool for dryland rehabilitation in northern Kenya. Specifically, the study aimed to assess technology adoption by the local community, investigate and compare quantitative information on vegetation structure in terms of density, spatial distribution and regeneration in enclosures and adjacent open areas and finally, to formulate a baseline for sustainable utilization of enclosures in Turkana County.

\section{MATERIALS AND METHODS}

\section{Study site}

The study site is located within Kalatum ranges of Kalokol division in Turkana County, North-West Kenya, about $30 \mathrm{~km}$ north of Lodwar town (Figure 1). Kalatum rangeland occupies an area of about $112 \mathrm{~km}^{2}$, which traditionally reserved as wet season grazing (Herlocker et al., 1994). However, this is no longer adhered to due to change of lifestyle. 
Soils are predominantly sandy but occasionally intercepted by patches of black cotton soils with high concentrations of carbonates and chlorides of sodium and carbonates (Van Bremen and Kinyanjui, 1992). Rainfall ranges between 150 and $200 \mathrm{~mm}$ per annum with peaks in April and October, while vegetation is classified as wooded annual grassland with a general vegetation cover of $41 \%$ (Herlocker et al., 1994).

\section{Establishment of research and community plots}

A 5-ha browse trial plot was initiated in 1986 at Kalatum ranges to investigate suitability and adaptability of different Australian and indigenous fodder tree species under different water harvesting techniques. Fencing was done using cedar posts and barbed wire. Micro-catchments of $5 \times 5 \mathrm{~m}$ and $10 \times 10 \mathrm{~m}$ were constructed and seedlings were planted. The indigenous species were Acacia mellifera, Acacia tortilis, Balanites aegyptiaca, Zizyphus mauritiana, Cordia sinensis and Dobera glabra. The exotic species were Acacia aneura, Atriplex aurionformis, Azandrachta indica, Parkinsonia aculeate and Acacia horosericea. Prior to plot establishment, a series of consultative meetings were held to discuss the project objectives with community members and a local resident engaged for surveillance to ensure non-intrusion of livestock into the trial plot.

Contact between the scientists and community members were maintained through collaborative periodic plots assessments and feedback meetings where ideas were freely discussed. During consultations, community members resolved to establish their own plots using available less palatable plant materials and using existing community norms.

\section{Data collection}

A line transect was established in 2011 across the fenced and unfenced areas. Plots of $20 \times 20 \mathrm{~m}$ were systematically laid along the transect which were estimated using a handheld Geographic Positioning System (GPS) according to Mengistu et al. (2005). A total of eighteen plots were established within the fenced areas and seven plots were established in the unfenced areas, as there was minimal variability in the unfenced areas. Smaller sub-plots of $5 \times 5$ $\mathrm{m}$ and $2 \times 2 \mathrm{~m}$ were nested at the centre of the main plots for saplings and herbaceous layer assessment respectively.

Trees data was collected in $20 \times 20$ m plots. Trees were classified as the woody plants whose respective height and diameter at breast height (dbh) were above $3 \mathrm{~m}$ and $2.5 \mathrm{~cm}$. (dbh is at $1.30 \mathrm{~cm}$ over the soil) Saplings data was collected through counting and measuring height in $5 \times 5 \mathrm{~m}$, plots, saplings were classified as the woody plants with height between 0.5 to $3 \mathrm{~m}$ and a dbh of $<2.5 \mathrm{~cm}$. Height and dbh were measured with a graduated measuring rod and diameter tape, respectively.

Herbaceous (including grass) and seedlings (woody species of height below $0.5 \mathrm{~m}$ ) were assessed in $2 \times 2 \mathrm{~m}$ sub-plots through, identification, counting and recording their numbers. Canopy and ground cover was also estimated in main and sub-plots, respecttively. Plant species were identified according to a checklist of plants for Turkana district (Morgan, 1981; Herlocker et al., 1994; Beentje, 2004). For species which could not be identified in the field, herbarium specimens were collected and identified through comparison with specimen in the regional herbarium at KEFRI Lodwar. The nomenclature of the identified species was crosschecked through international plant names index website (www.ipni.org).

\section{Assessment of plots expansion}

GPS points were taken along the perimeter of initial research plot and expanded community plots. The data points were entered to
Geographic Information Systems (GIS) software (Arch GIS); polygons were drawn by joining the points and polygon areas generated by the software. Focussed group discussions were held with the communities in surrounding villages to document rules and regulations that guide the management and maintenance of community enclosures.

\section{Data analysis}

Descriptive synthesis and analysis of data was carried out using Microsoft Excel and SPSS version 19. Average percentage cover, relative abundance and frequency of each herbaceous species was obtained using the following equations (Herlocker, 2005):

Average percentage cover $=$ Total percentage cover of species in the plots/number of plots having species $\times 100$

Relative abundance $=$ Number of individuals of the species recorded/total number of plants in all the plots $\times 100$

Relative frequency $=$ Number of sample plots in which the species occurred/total number of plots $\times 100$

The density of woody plant species was obtained by calculating the number of individuals per hectare and paired sample t-test used to compare between enclosure and open areas. The diversity was obtained using Shannon diversity index $\left(H^{\prime}\right)$ as follows (MacDonald, 2003):

$\left(H^{\prime}\right)=-\sum p i \ln p i$

Where $p i=n_{i} / N$, the proportion of the ith species and In is the natural logarithm. The index assumes that each representative sample species has an equal chance of being included in each sampling point.

\section{RESULTS}

\section{Species composition}

A total of 31 plant species within 20 families were identified both in the enclosures and in the open grazing areas. The plant composition consisted of $20 \%$ grasses, $30 \%$ trees/shrubs and $50 \%$ herbs. Eighty percent of identified plant species were palatable to livestock. Fourteen species were recorded both in the enclosures and in the open rangelands while twelve species were found in the enclosures only, in addition, five species occurred only in the open area (Tables 1 and 2).

\section{Woody species density, diversity and population structure}

The dominant woody species recorded was Acacia tortilis, with a density of 204 trees and 74 trees ha ${ }^{-1}$ inside the enclosure and in open areas-respectively (Table 2). Density was significantly different between enclosure and open areas $(t=3.05 \mathrm{df}=7 p=0.019)$. Other species recorded include Acacia reficiens, Salvadora persica and Zizyphus mauritiana. Among the indigenous and exotic 
Table 1. Herbs and seedlings found in enclosure and open area.

\begin{tabular}{lcccccc}
\hline & \multicolumn{3}{c}{ Enclosure } & \multicolumn{3}{c}{ Open area } \\
\cline { 2 - 7 } Specie & $\begin{array}{c}\text { Mean } \\
\text { cover } \\
(\%)\end{array}$ & $\begin{array}{c}\text { Relative } \\
\text { abundance } \\
(\%)\end{array}$ & $\begin{array}{c}\text { Relative } \\
\text { Frequency } \\
(\%)\end{array}$ & $\begin{array}{c}\text { Mean } \\
\text { cover } \\
(\%)\end{array}$ & $\begin{array}{c}\text { Relative } \\
\text { abundance } \\
(\%)\end{array}$ & $\begin{array}{c}\text { Relative } \\
\text { Frequency } \\
(\%)\end{array}$ \\
\hline Indigofera cliffordiana Gillett. & - & - & - & 0.14 & 0.17 & 14.29 \\
Seddera hirsuta Hall.f. & 0.40 & 0.92 & 11.11 & 0.71 & 0.17 & 14.29 \\
Barleria eranthamoides C.B.C.L (Cl.) & 0.06 & 0.1 & 5.56 & 0.14 & 0.17 & 14.29 \\
Evolvulus alsinoides (L) L.plate & 1.70 & 5.75 & 11.11 & 0.86 & 1.89 & 28.57 \\
Ruella patula Jacq. (Ruellia) & - & - & - & 5.71 & 6.56 & 28.57 \\
Aristida mutabilis Trin \& Rupr. & - & - & - & 1.40 & 7.77 & 14.29 \\
Heliotropium longiflorum Jaub and Spach. & 1.00 & 6.47 & 16.67 & 0.14 & 0.86 & 14.29 \\
Acacia tortilis (Forssk) Hayne & 0.06 & 0.10 & 5.56 & - & - & - \\
Ornithogulum Tennifolium (tennifolium) & 0.12 & 1.13 & 11.11 & - & - & - \\
Aristida adscensionis Walter & 1.20 & 5.85 & 16.67 & - & - & - \\
Tribulus cistoides L. & 0.06 & 0.21 & 11.11 & - & - & - \\
Indigofera swaziensis Bolus & 0.20 & 0.92 & 22.22 & - & - & - \\
Dactyloctenium aegyptium (L.) K. Ritch. & 0.06 & 5.34 & 5.57 & - & - & - \\
(Will.) & 2.50 & 26.39 & 11.11 & - & - & - \\
Ocimum suave Willd & 0.40 & 1.33 & 5.56 & 2.14 & 22.62 & 28.57 \\
Pupalia lappacea L. & 0.06 & 0.10 & 5.56 & - & - & - \\
Solanum coagulans Forssk & 0.06 & 0.10 & 5.56 & - & - & - \\
Acacia reficiens Wawra\& Peyr & 1.20 & 0.41 & 5.56 & - & - & - \\
Acacia nubica Benth & 1.70 & 7.75 & 11.11 & & - & - \\
Fersetia stenoptera Hochst & 0.17 & 12.32 & 5.56 & - & - & - \\
Eragrostis porosa Nees. & - & - & - & 5.71 & 2.42 & 14.29 \\
Duosperma eremophilum L. (Willd) & 36.30 & 26.59 & 50.00 & 4.14 & 15.89 & 28.57 \\
Chrysopogon plumulosus Hochst. & 0.06 & 0.1 & 5.56 & - & - & - \\
Hyphaene compressa H. Wendl. & - & - & - & 5.00 & 4.45 & 14.29 \\
Cyperus rotundus L. & & & & & - \\
\hline
\end{tabular}

Table 2. Density (trees/ha) of dominant tree species.

\begin{tabular}{lcc}
\hline Specie & Enclosure & Open area \\
\hline Acacia tortilis (Forssk) Hayne & 204 & 74 \\
Acacia reficiens Wawra\& peyr & 89 & 7 \\
Acacia nubica Benth. & 76 & 4 \\
Balanites aegyptica (L.) Del. & 60 & 4 \\
Salvadora persica L. & 45 & 2 \\
Zizyphus mauritiana Lam. & 13 & 0 \\
Acacia mellifera (Vahl) Benth. & 4 & 1 \\
Cadaba rotundifolia Forssk. & 0 & 7 \\
\hline
\end{tabular}

species planted; Z. mauritiana, Acacia mellifera and $A$. tortilis has been recruited successfully through microcatchments. Mean Shannon diversity index $(H)$ was 1.6 and 1.0 for enclosure and open areas, respectively. Saplings were only recorded in the enclosures where $A$. reficiens, Acacia nubica and $A$. tortilis were the dominant species. Distribution of dbh classes indicates a higher proportion of lower diameters with $75 \%$ of woody species having diameters less than $5 \mathrm{~cm}$ (Figure 2). This scenario is absent outside the enclosure since diameter distribution could not be formulated due to low number and diversity of woody species recorded. 


\section{Herbaceous and seedlings cover, abundance and frequency}

The ground cover was dominated by Chrysopogon plumulosus with 36 and $4 \%$ within and outside the enclosures, respectively. Duosperma eremophilum, a perennial herb was mostly found in open rangelands. The

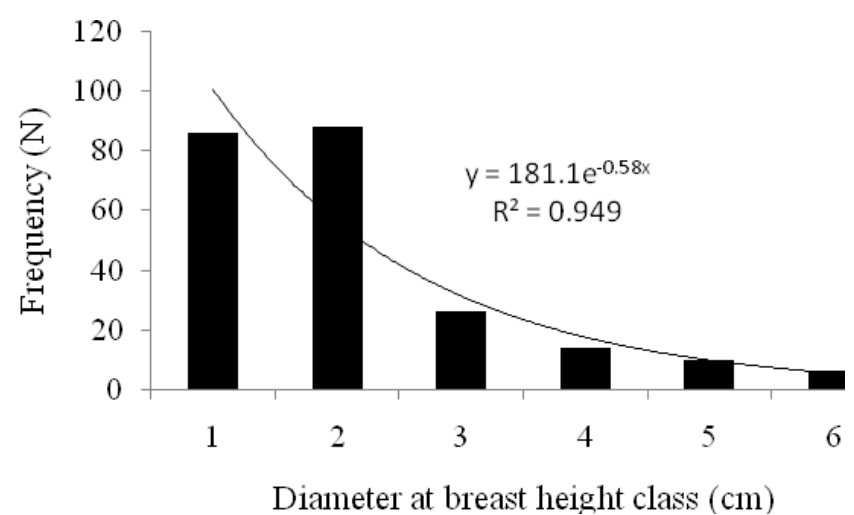

Figure 2. Diameter class distribution of trees in the enclosure (1 $=2.5-4.9,2=5.0-7.4,3=7.5-9.9,4=10-12.4,5=12.5-14.9,6=$ $\geq 15$ ).

most abundant species in the herbal layer was $C$. plumulosus, Ocimum suave and Eragrostis porosa with a relative abundance of 27,26 and $12 \%$, respectively in the enclosure. In the open rangelands, Pupalea lappaceae was the most abundant species (22\%). The seedlings of A. tortilis, A. nubica, A. reficiens and Hyphaene compressa had a relative frequency of $6 \%$ within the enclosure whereas C. plumulosus, P. lappaceae, Evolvulus alsinoides and Ruela patula dominated in the open.

\section{Technology adoption}

The study indicates an increase of the initial fenced area of 5-ha to an extensive area of 23-ha as outlined in Figure 3. Local community adopted the use of locally available materials and traditional rules to keep off the livestock in areas agreed through participatory consultations. Community plot 1 which is an extension of the original plot was established from 1989 to 1993 whereas community plot 2 and 3 were established from 1995 to 2002.

During focussed group discussions, traditional rules and regulations guiding the management and maintenance of enclosures were summarized as follows:

\footnotetext{
- Decisions are carried out by council of elders selected from surrounding villages;

- Young seedlings were protected from damage during dry season grazing by sick and aged small livestock such as goats and sheep;
}

- Surveillance of the enclosure was done by sending young men and sometimes the whole community;

- Harvesting of trees is prohibited, but pruning of trees can be done during construction of temporary livestock sheds;

- Harvesting of highly valued Acacia pods (ngitit) was only allowed under supervision by the council of elders;

- Severe penalties like revoking grazing rights for the enclosure are imposed on community members who violate the established grazing rules.

\section{DISCUSSIONS}

The contrasting vegetation patterns between the fenced and unfenced plots referred to in this study (Table 2 and Figure 3) attest for the effectiveness of enclosures in range rehabilitation. The enclosures have marginally higher diversity index than open areas. Although the species diversity is low in enclosures, it is still above minimum threshold of 1.5 in sustainable natural ecosystems (Macdonald, 2003). Although periodical changes of vegetation trends was not factored in this study, similar studies in Northern Ethiopia shown a contrast of area enclosures aged about 10 years and open grazing areas (Mengistu et al., 2005). The high diversity values of enclosures indicate the technologies' significance in conservation of genetic resources of woody species which are under heavy threat of local extermination. Furthermore, they play crucial role in provision of browse during dry spells in this locality.

The higher density of $A$. tortilis in the enclosed areas could be due to accumulation of seed from goat droppings, while foraging along the perimeter of social fence during 'dry season grazing'. This concurs with a previous study that revealed a higher recruitment of the species in abandoned livestock "kraals" (Reid and Ellis, 1995). Goats which form majority of livestock population in Turkana County normally feeds on the $A$. tortlis pods but the seeds are not digested, but are excreted in the droppings and germinate later, although if the young seedlings are not enclosed they are browsed. The contrasting status of $A$. tortilis seedlings and saplings can be associated with seedling protection in the enclosure as opposed to seedling damage through browsing in the unfenced areas.

The presence of Aristida mutabilis, Aristida adscensions and Eragrostis porosa grass in the enclosures only, which are highly valued among the pastoralists, demonstrates the significance of enclosing degraded areas. The low percentage of seedlings of woody species which accounted for $10 \%$ could be due to competition from other plants and moisture stress. However, in an area receiving an average rainfall of $150 \mathrm{~mm}$ per annum, the seedling proportion is adequate if it can reach maturity. It is worthy to note that no seedlings were found in the open rangelands during the period of study hence enclosing portions of degraded rangeland could greatly 


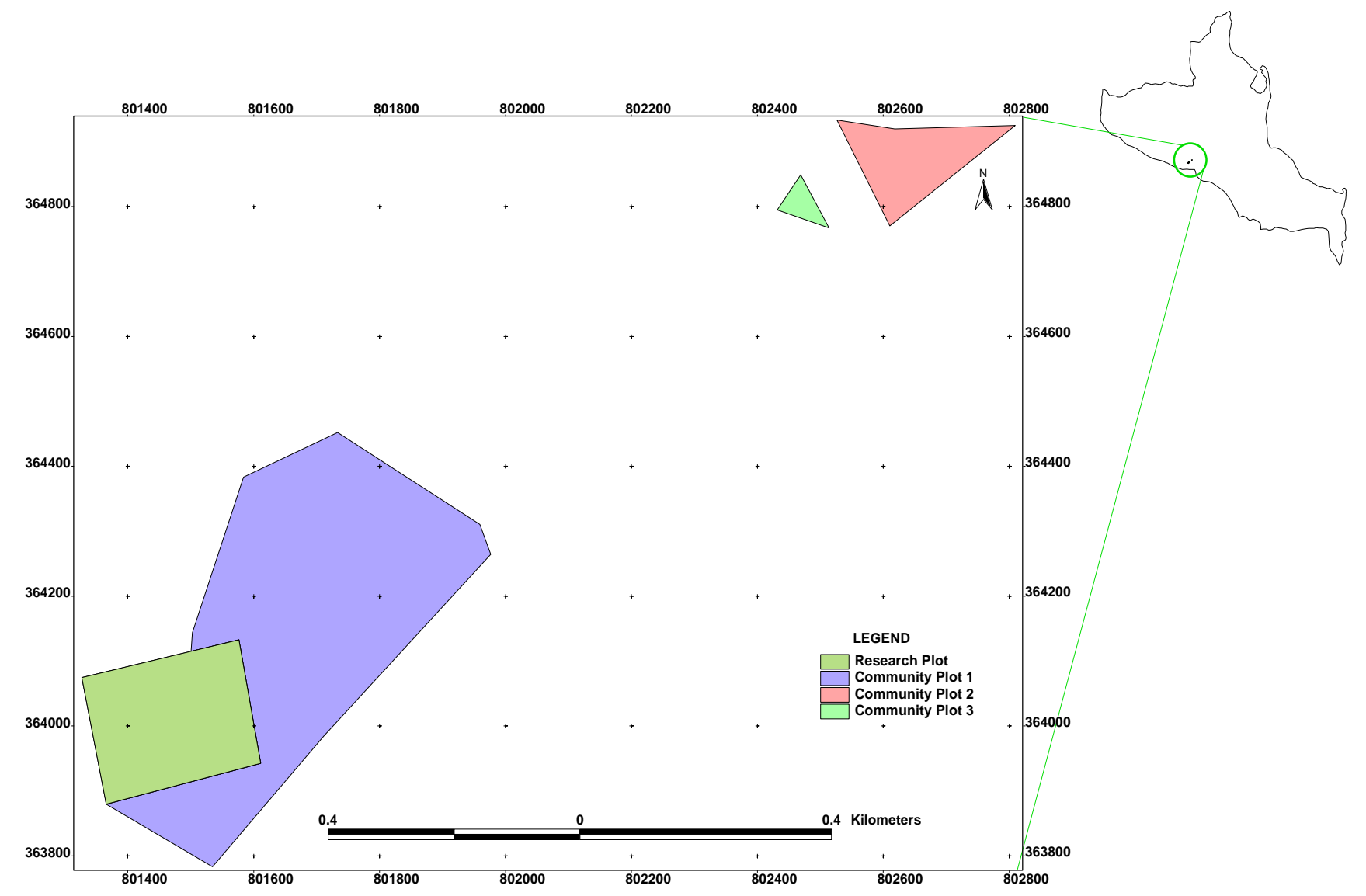

Figure 3. Location and extent of research and community plots in the project area.

enhance regeneration of woody species and consequently hasten the rehabilitation of these sites. High presence of Pupalea lappaceae which is an annual herb indicates low preference by the livestock. However Duosperma eremophilum is highly preferred by livestock but is mostly found in range lands. It is highly drought tolerant and sprouts quickly after the grazing period. It is conceivable that the species is a poor competitor and this is the likely reason for its low abundance in the enclosed areas.

Diameter distribution revealed a relatively large number of individuals in lower diameter class followed by gradual decline in higher diameter classes (Figure 2). This indicates a sustainable regeneration status within the enclosures. The absence of saplings in the open rangelands can be attributed to the browsing by livestock and human disturbance.

Planting of trees in micro-catchments resulted in successful establishment of indigenous tree species. This shows the importance of water harvesting structures due to limited and unreliable amount of rainfall in this locality. The study also revealed poor long term survival of exotic species which concurs with studies of Olukoye et al. (2003)

Strong traditional systems in management of natural resources have been demonstrated by the community through expansion of original research plot to an extensive enclosure, which is the only green spot within this locality. The study concurs with studies of Barrow (1996) that documented the evolution of traditional range management practices among the Turkana community and "Sukuma" of Tanzania who practice customary tree resource management system known as "ngitili". Collection of woody material was strictly supervised by elders to ensure materials were from dead branches and less palatable species such as Cadaba rotundifolia. Jama and Zeila (2005) emphasises the importance of involving local community since they understand the interconnectedness, peculiarities and complexities of dryland ecosystems especially their rangelands and woodlands.

\section{Conclusions and recommendations}

The results of this study show that, with proper management and involvement of all stakeholders including local community during project designing, planning and implementation, enclosures can contribute to rehabilitation of degraded areas. Use of traditional rules can be adopted easily as compared to physical fences during establishment of community enclosures. However, there is need to 
carry out cost benefit analysis to steer up scaling of this technology among different pastoral communities in the dry lands of Kenya.

\section{ACKNOWLEDGEMENTS}

The authors thank Government of Kenya through Kenya Forestry Research Institute for financial and logistic support. The contributions of Julius Kaseberi, Jacob Kimani, Giathi Gitehi, Simon Wairungu and Dr. James Kimondo during data collection and preparation of manuscripts are highly appreciated. Special thanks also go to the pastoralists for their hospitality and participation during field data collection.

\section{REFERENCES}

Barrow EGC (1996). The drylands of Africa: Local participation in tree management, Initiative Publishers, Nairobi. pp. 268.

Beentje H (1994) Kenya trees, shrubs and lianas, National Museums of Kenya, Nairobi. pp.722.

Government of Kenya (2007). Kenya Vision 2030: A globally competitive and prosperous Kenya, Ministry of Planning and Vision 2030, Government Printers. pp. 136

Herlocker D (1995). Range resource monitoring: field and office guidelines, Range Management Handbook of Kenya vol.III, Signal Press Ltd., Nairobi, p. 60

Herlocker D, Shaaban SB, Wilkes S (1994). Range management handbook of Kenya 2(9) Turkana District, Republic of Kenya, Ministry of Agriculture, Livestock Development and Marketing, Nairobi. pp.189.

Jama B, Zeila A (2005). Agroforestry in the drylands of eastern Africa: a call to action. ICRAF Working Paper no. 1, World Agroforestry Centre. pp.29

Kariuki JG, Machua J, Luvada AM, Kigomo JN, Muindi FK, Macharia EW (2007). Baseline survey of woodland utilization and degradation around Kakuma refugee camp, KEFRI/JOFCA Report. pp. 60.

Macdonald G (2003). Biogeography: Introduction to space, time and life. John Wiley and Sons, Los Angeles. pp. 518.
Mengistu T, Teketay D, Hulten H, Yemshaw $Y$ (2005). The role of enclosures in the recovery of woody vegetation in the degraded dryland hillsides of central and northern Ethiopia. J. Arid Environ. 60: 259-281.

Morgan WTE (1981) Ethno-botany of Turkana: Use of plants by a pastoral people and their livestock in Kenya. Econ. Bot. 35: 96-130

Okoti M, Ngethe JC, Ekaya WN, Mbuvi DM (2004) Land use ecology and socio-economic changes in a pastoral system. J. Hum. Ecol, 16(2): 83-89

Olukoye GA, Wamicha WN, Kinyamario Jl (2003). Assessment of the performance of exotic and indigenous tree and shrubs species for rehabilitating saline soils of Northern Kenya. Afr. J. Ecol. 41: 164-170.

Reid RE, Ellis JE (1995). Impacts of pastoralist on woodlands in South Turkana, Kenya Livestock -Mediated Tree Recruitment. Ecol. Appl. 5: 978-992

Sitters J, Heitkoing IMA, Holmgren M, Ojwan GSO (2009). Herded cattle and wild grazers partition water but share forage resources during dry season in East Africa savannas. Biol. Conserv. 142: 738750.

UNEP (2000). Devastating drought in Kenya: Environmental impacts and Responses, Nairobi, Kenya. pp. 159

Van Bremen H, Kinyanjui HCK (1992). Soils of Lodwar area: An inventory, an evaluation of present land use and recommendations for future land use. Reconnaissance Soils Survey Report No. R17 Soil Survey Nairobi Kenya 